\title{
TWO-DIMENSIONAL GEOMETRIC OPTIMIZATION OF AN OSCILLATING WATER COLUMN CONVERTER IN LABORATORY SCALE
}

\author{
M. N. Gomes ${ }^{\text {a, b,* }}$, \\ C. D. Nascimento ${ }^{a}$, \\ B. L. Bonafini ${ }^{a}$, \\ E. D. Santos ${ }^{c}$, \\ L. A. Isoldi ${ }^{c}$, \\ and L. A. O. Rochab \\ ${ }^{a}$ Instituto Federal do Paraná \\ Campus Paranaguá \\ Rua Antônio Carlos Rodrigues 453, Bairro \\ Porto Seguro, Paranaguá, PR, Brasil. \\ ${ }^{\mathrm{b}}$ Universidade Federal do Rio Grande do Sul \\ Programa de Pós-Graduação em Engenharia \\ Mecânica \\ Rua Sarmento Leite, 425, CP. 90050-170, \\ Porto Alegre, RS, Brasil. \\ ${ }^{\mathrm{c}}$ Universidade Federal do Rio Grande \\ Escola de Engenharia \\ Av. Itália, km 8, Bairro Carreiros \\ CEP 96.201-900, Rio Grande, Brasil. \\ "mateus.gomes@ifpr.edu.br
}

ABSTRACT

The present paper presents a two-dimensional numerical study about the geometric optimization of an ocean Wave Energy Converter (WEC) into electrical energy that has as operational principal the Oscillating Water Column (OWC). To do so, the Constructal Design fundamentals were employed to vary the degree of freedom $H_{1} / L$ (ratio between height and length of the OWC chamber), while the other degree of freedom $\mathrm{H}_{2} / l$ (ration between height and length of chimney) was kept constant. The OWC chamber area $\left(\phi_{1}\right)$ and the total OWC area $\left(\phi_{2}\right)$ are also kept fixed, being the problem constraints. In this study was adopted a regular wave with laboratory scale dimensions. The main goal was to optimize the device's geometry aiming to maximize the absorbed power when it is subjected to a defined wave climate. For the numerical solution it was used the Computational Fluid Dynamic (CFD) commercial code FLUENT $^{\circledR}$, which is based on the Finite Volume Method (FVM). The multiphasic Volume of Fluid (VOF) model was applied to treat the water-air interaction. The computational domain was represented by an OWC device coupled into a wave tank. Thereby, it was possible to analyze the WEC subjected to regular wave incidence. An optimal geometry was obtained for $\left(H_{1} /\right)_{\mathrm{L}}=$ 0.84 , being this one approximately ten times more efficient then the worst case $\left(H_{1} / L=0.14\right)$, showing the applicability of Constructal Design in this kind of engineering problem.

Keywords: Constructal Design, wave energy, oscillating water column (OWC), geometric optimization.

\section{NOMENCLATURE}

A cross sectional area of the chimney, $\mathrm{m}^{2}$

$b \quad$ OWC device width, $\mathrm{m}$

$C_{g} \quad$ celerity

$f \quad$ fraction volumetric

$g$ acceleration due to gravity, $\mathrm{m} / \mathrm{s}^{2}$

$h$ depth, $\mathrm{m}$

$H$ height wave, $\mathrm{m}$

$H_{1}$ height chamber, $\mathrm{m}$

$\mathrm{H}_{2}$ height chimney chamber, $\mathrm{m}$

$\mathrm{H}_{3} \quad$ lip, m

$H_{T} \quad$ height wave tank, $\mathrm{m}$

$k \quad$ wave number, $\mathrm{m}^{-1}$

$l \quad$ OWC chimney length, $\mathrm{m}$

$L \quad$ OWC device length, $m$

$L_{T} \quad$ wave tank length, $\mathrm{m}$

$\dot{m}$ mass flow rate, $\mathrm{kg} / \mathrm{s}$

$p \quad$ static pressure, $\mathrm{Pa}$

$P_{\text {hyd }}$ hidropneumatic power,Pa

$P_{\text {air }} \quad$ static pressure in the OWC chimney, $\mathrm{Pa}$

$t$ time, s

$T \quad$ wave period, $\mathrm{s}$

$u \quad$ velocity component in $\mathrm{x}, \mathrm{m} / \mathrm{s}$

$v_{\text {air }} \quad$ velocity in chimney, $\mathrm{m} / \mathrm{s}$

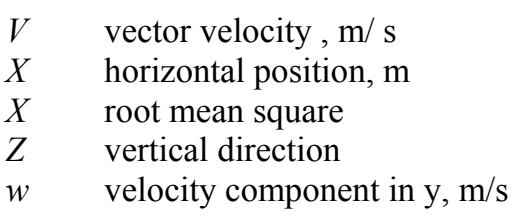

\section{Greek symbols}

$H \quad$ elevation of the wave, $\mathrm{m}$

$\lambda$ wavelength, $\mathrm{m}$

$\rho$ density, $\mathrm{kg} / \mathrm{m}^{3}$

$\phi \quad$ potential function

$\phi_{1} \quad$ OWC chamber area, $\mathrm{m}^{2}$

$\phi_{2}$ total OWC area, $\mathrm{m}^{2}$

$\mu \quad$ viscosity, $\mathrm{kg} / \mathrm{m} . \mathrm{s}$

$\omega \quad$ circular frequency of wave

\section{INTRODUCTION}

Currently, one of the greatest challenges is to supply the world energetic demand. In this context, there are several discussions about generation and consumption of electrical energy. One of the main variables to define the development indices of a 
country is the population's access facility to the infrastructure services, as basic sanitation, transport, telecommunications and energy (ANEEL, 2008).

Based on these aspects, recently the countries have been invested in the explanation of new energy sources, especially in so-called renewable energy sources. Among them, the conversion of ocean wave energy into electrical energy has been highlighted. The energy contained in oceans can have different origins, generating different classifications. No doubt, the most relevant are the ocean tidal energy (caused by interaction between the gravitational fields of sun and moon), the ocean thermal energy (direct consequence of solar radiation incidence), the ocean currents energy (originated in the gradients of temperature and salinity and tidal action) and, finally, the ocean wave energy (which is result of the wind effect over the ocean surface). Once generated, the waves can travel thousands of miles on the high seas practically without energy loss. In coastal regions the wave energy density decreases due its interaction with the seabed. The wave power is proportional to its squared amplitude and its period. Waves with high amplitude (around $2 \mathrm{~m}$ ) and with high periods (7 to $10 \mathrm{~s}$ ) normally exceed $50 \mathrm{~kW}$ per meter of wave front (Cruz e Sarmento, 2004).

The criterion usually adopted to classify the WEC devices is related with its installation distance from the coast. In accordance with this classification, the WECs are grouped in: onshore (integrated with coastal structures, facilitating the access), near-shore (devices located in depths of 8 to $20 \mathrm{~m}$ ) and offshore (installation depths upper than 25m) (Cruz e Sarmento, 2004).

Another possible classification is associated with the principle adopted to transform the wave energy into electricity, existing three principal groups: Oscillating Water Column (OWC), Wave Activated Bodies (WAB) and Overtopping Devices (OTD). This classification does not end the possibility of other operating principle to be able for convert the ocean wave energy, being an example the submerged plate device (Carter, 2005).

Therefore, the main goal of the present work was to optimize the geometry of an OWC device aiming to improve the incident wave energy harnessing. It is important to mention, that this investigation was conduct considering the operating principle of OWC devices. To do so, it was applied the Constructal Design technique which is based on the Constructal Theory developed by Adrian Bejan (Bejan, 2000; Bejan and Lorente, 2008; Bejan and Zane, 2012).

The Constructal theory explain deterministically how the generation of shape in flow structures of nature (river basins, lungs, atmospheric circulation, animal shapes, vascularized tissues, etc) based on an evolutionary principle of flow access in time. That principle is the Constructal law: for a flow system to persist in time (to survive), it must evolve in such way that it provides easier and easier access to the currents that flow through it (Bejan and Lorente, 2008).

Concerning the engineering problems, the Constructal Design (Constructal Theory for optimization of several systems, e.g., engineering) has been broadly applied for the study of fluid mechanics and heat transfer. However, only few works involving the WECs are found in literature.

In Lopes et al. (2011) the Constructal Design was used for the geometric optimization of an OWCWEC, varying the degree of freedom defined by the ratio between the chamber length and the chimney length. In addition to this study, Machado et al. (2011) also applied Constructal Design with the purpose to optimize the geometry of an OTD-WEC considering the ratio between the height of the ramp and its length as the degree of freedom analyzed. On both studies the results indicated that the Constructal Design can be used for the WEC's geometrical optimization in a satisfactory way.

So, in the present work the Constructal Design was applied to an OWC device in order to optimize the degree of freedom $H_{l} / L$ (ratio between the height and the length of its chamber) being the objective function to maximize the harnessing of incident wave power, i.e., the conversion of this power into hydropneumatic power. The other degree of freedom $\mathrm{H}_{2} / \mathrm{l}$ (ratio between the height and length of the chimney) was kept fixed, as well as, the OWC chamber area $\left(\phi_{1}\right)$ and the total OWC area $\left(\phi_{2}\right)$, which are the two problem geometric constraints.

The computational domain (OWC coupled to a wave tank) was created and discretized in GAMBIT $\AA$ software, while the numerical simulations were carried out by means a computational modeling implemented in the Computational Fluid Dynamic (CFD) commercial software FLUENT ${ }^{\circledR}$, which is based on the Finite Volume Method (FVM) (FLUENT, 2007; Versteeg e Malalasekera, 2007). The multiphase Volume of Fluid (VOF) model was employed for the treatment of water-air interaction, as already performed by: Gomes (2010), Horko (2007), Liu et al. (2008a), Liu et al. (2008b), Liu et al. (2011) and Ramalhais (2011). The wave generation was promoted by the imposition of the vertical and horizontal velocity wave components as boundary condition.

\section{COMPUTATIONAL MODELING OF OWC DEVICES}

\section{Oscillating Water Column}

The Oscillating Water Column devices are, basically, hollow structures partially submerged, with an opening to the sea below the water free surface, as can be seen in Fig. 1. In accordance with Cruz and Sarmento (2004), the electricity generation process has two stages: when the wave reaches the structure, 
its internal air is forced to pass through a turbine, as a direct consequence of the augmentation of pressure the chamber; and when the wave returns to the ocean, the air again passes by the turbine, but now being sucked from the external atmosphere, due to the chamber internal pressure decreasing. So, to use these opposite air movements usually the Wells turbine is employed, which has the property of maintaining the rotation direction irrespective of the flow direction. The set turbine/generator is the responsible for the electrical energy production.

\section{Computational Domain}

Based on the of the period $(T)$, height $(H)$ and propagation depth $(h)$ of the wave, it is possible to define the length $\left(L_{T}\right)$ and height $\left(H_{T}\right)$ of the wave tank (Fig. 1). There is no a general rule to establish these dimensions, however some aspects must be taken into account. The wave propagation depth is adopted as the wave tank mean water level, i.e., the wave tank water depth $(h)$. For the wave tank length it is necessary to consider the wave length, being recommended that the wave tank length has at least five times the wave length. Thereby, a numerical simulation without effects of wave reflection can be performed, during a satisfactory time interval and without an unnecessarily increase of the computational domain length (which would cause an increase in the computational effort and in the processing time). Regarding the wave tank height, the propagation depth and the height of the wave must be considered. So, it is possible to define the wave tank height as the propagation depth plus three times the wave height.

Table 1 presents the characteristic dimensions used in the present work. It is worth to mention that the $\mathrm{H}_{3}$ dimension is related to the installation depth (lip) of the OWC-WEC, i.e., how much the device is submerged. This value is measured from the water free surface level. Here, a lip with one quarter of wave height was adopted, in accordance with Gomes (2010).

Table 1. Characteristic dimensions of the problem.

\begin{tabular}{cc}
\hline Characteristic Dimensions & Values \\
\hline Wave period $(T)$ & $0.800 \mathrm{~s}$ \\
Wave height $(H)$ & $0.140 \mathrm{~m}$ \\
Wave length $(\lambda)$ & $1.000 \mathrm{~m}$ \\
Wave propagation depth $(h)$ & $0.500 \mathrm{~m}$ \\
Wave tank length $\left(L_{T}\right)$ & $5.000 \mathrm{~m}$ \\
Wave tank height $\left(H_{T}\right)$ & $0.800 \mathrm{~m}$ \\
OWC Lip $\left(H_{3}\right)$ & $0.465 \mathrm{~m}$ \\
\hline
\end{tabular}

\section{Boundary Conditions}

As can be observed in Fig. 1, the wave maker is placed in the left side of the wave tank. For the regular wave generation it was employed the called
Function Methodology (Gomes et al. 2009). This methodology consists in the employment of vertical and horizontal components of wave velocity as boundary conditions (velocity inlet) of the computational model, by means an User Defined Function (UDF) in the FLUENT ${ }^{\circledR}$ software. These velocity components vary as functions of space and time and are based on the Second Order Stokes Theory. It is important to emphasize that in accordance with Chakrabarti (2005) the wave proposed in the present work is classified as a High Order wave. However, as the influence of the high order terms can be neglected in the wave generation modeling without any significantly loss, the wave velocity components used are given by:

$$
\begin{aligned}
& u=\frac{H}{2} g k \frac{\cosh (k z+k h)}{\omega \cosh (k h)} \cos (k x-\omega t)+\frac{3}{4}\left(\frac{H}{2}\right)^{2} \operatorname{\omega k} \frac{\cosh 2 k(k+z)}{\operatorname{senh}^{4}(k h)} \cos 2(k x-\omega t) \\
& w=\frac{H}{2} g k \frac{\operatorname{senh}(k z+k h)}{\omega \cosh (k h)} \operatorname{sen}(k x-\omega t)+\frac{3}{4}\left(\frac{H}{2}\right)^{2} \omega k \frac{\operatorname{senh} 2 k(k+z)}{\operatorname{senh}^{4}(k h)} \operatorname{sen} 2(k x-\omega t)
\end{aligned}
$$

where: $H$ is the wave height $(\mathrm{m}) ; g$ is the gravitational acceleration $\left(\mathrm{m} / \mathrm{s}^{2}\right) ; l$ is the wave length $(\mathrm{m}) ; k$ is the wave number given by $k=2 \pi / \lambda\left(\mathrm{m}^{-1}\right), h$ is the depth (m), $T$ is the wave period (s), $\omega$ is the frequency given by $\omega=2 \pi / T(\mathrm{rad} / \mathrm{s}), x$ is the streamwise coordinate $(\mathrm{m}), t$ is the time (s) and $z$ is the normal coordinate $(\mathrm{m})$.

Concerning the other boundary conditions, in the upper surfaces of wave tank and chimney and above the wave maker (dashed line in Fig. 1) it was considered the atmospheric pressure (pressure outlet). In the bottom and right side of computational domain a no slip and impermeability conditions (wall) were adopted.

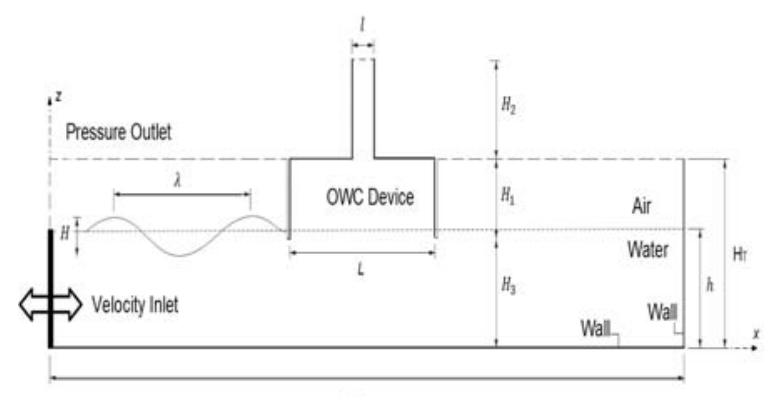

$L_{\tau}$

Figure 1. Schematic representation of the computational domain.

\section{CONSTRUCTAL DESIGN FORMULATION}

Basically, to apply the Constructal Design for the geometric optimization of a physical system it is required an objective function (a quantity that will be optimized), degrees of freedom (geometric parameters which may vary during the optimization process) and geometric constraints (parameters that are kept constant during the optimization process). 
In the present work the objective function was to maximize the OWC available power, varying the degree of freedom $H_{1} / L$ (ratio between the height and length of the chamber) (see Fig. 1). Two global constraints were considered: the OWC chamber area $\left(\phi_{1}\right)$ and the total OWC area $\left(\phi_{2}\right)$, which are defined as:

$\phi_{1}=H_{1} L$

$\phi_{2}=\phi_{1}+H_{2} l$

Besides, the other degree of freedom $\mathrm{H}_{2} / l$ (ratio between the height and the length of the chimney) was kept constant for all numerical simulations.

\section{MATHEMATICAL AND NUMERICAL MODELS}

The Volume of Fluid (VOF) method is a multiphase numerical model that can be used to treat the interaction between water and air inside the wave tank. In this method, the free surface can be identified by the volume fraction $(f)$ variable. In each mesh cell (element), if $f=1$ the cell is full of water, when $f=0$ the cell contain only air and if $0<f<1$ the cell has water and air simultaneously. Moreover, when the VOF method is used a single set of momentum and continuity equations is applied to all fluids, and the volume fraction of each fluid in every computational cell (control volume) is tracked throughout the domain by the addition of a transport equation for the volume fraction. Thus, the model is composed by the continuity, momentum and volume fraction equations, which are respectively given by (FLUENT, 2006; Gomes et al., 2009):

$\frac{\partial \rho}{\partial t}+\nabla \cdot(\rho \vec{v})=0$

$\frac{\partial}{\partial t}(\rho \vec{v})+\nabla \cdot(\rho \overrightarrow{v v})=-\nabla p+\nabla \cdot(\bar{\tau})+\rho \vec{g}$

$\frac{\partial(f)}{\partial t}+\nabla \cdot(f \vec{v})=0$

being: $\rho$ the fluid density $\left(\mathrm{kg} / \mathrm{m}^{3}\right), t$ the time (s), $\vec{v}$ the flow velocity vector $(\mathrm{m} / \mathrm{s}), p$ the static pressure (Pa), $\bar{\tau}$ the stress tensor $(\mathrm{Pa})$ and $\vec{g}$ the gravitational acceleration $\left(\mathrm{m} / \mathrm{s}^{2}\right)$.

The solver is pressure-based and all simulations were performed by upwind and PRESTO for spatial discretizations of momentum and pressure, respectively. The velocity-pressure coupling is performed by the PISO method, while the GEORECONSTRUCTION method is employed to tackle with the volumetric fraction. Moreover, underrelaxation factors of 0.3 and 0.7 are imposed for the conservation equations of continuity and momentum, respectively. All numerical simulations were carried out in a computer AMD Athlon 2 Core with $3.0 \mathrm{~Gb}$ of RAM. To reduce the simulation time the parallel processing technique was adopted (FLUENT, 2006)

\section{RESULTS AND DISCUSSIONS}

Computational modeling using the VOF method has been largely employed to numerically simulate the WECs. Validations and verifications of these methodologies can be found in Horko (2007), Liu et al. (2008a), Liu et al. (2008b), Gomes et al. (2009), Gomes (2010), Ramalhais (2011), Liu et al. (2011) e Gomes et al. (2012). For this reason, the validation/verification process will not be presented.

The parameters kept constant in all simulations were: $\phi_{1}=0.14, \phi_{2}=0.20$ e $H_{2} / l=3.0$. Thus, varying the degree of freedom $H_{1} / L$ it was possible to calculate the dimensions of OWC device, being these values showed in Table 2. Highlighting that for the choice of $\phi_{1}$ value was taking into account the initial situation (Case 1), in which the OWC length $(L)$ is equal to the length $(\lambda)$ of incident wave.

Table 2. OWC geometric variations.

\begin{tabular}{cccccc}
\hline Case & $H_{1} / L$ & $L(\mathrm{~m})$ & $H_{1}(\mathrm{~m})$ & $l(\mathrm{~m})$ & $H_{2}(\mathrm{~m})$ \\
\hline 1 & 0.14 & 1.0000 & 0.1400 & 0.1414 & 0.4242 \\
2 & 0.28 & 0.7071 & 0.1979 & 0.1414 & 0.4242 \\
3 & 0.42 & 0.5773 & 0.2424 & 0.1414 & 0.4242 \\
4 & 0.56 & 0.5000 & 0.2800 & 0.1414 & 0.4242 \\
5 & 0.70 & 0.4472 & 0.3130 & 0.1414 & 0.4242 \\
6 & 0.84 & 0.4082 & 0.3429 & 0.1414 & 0.4242 \\
7 & 0.98 & 0.3779 & 0.3704 & 0.1414 & 0.4242 \\
8 & 1.26 & 0.3333 & 0.4200 & 0.1414 & 0.4242 \\
9 & 2.24 & 0.2500 & 0.5600 & 0.1414 & 0.4242 \\
\hline
\end{tabular}

In all simulated cases it was used a mesh generated by quadrilateral elements with dimensions $0.01 \mathrm{~m} \times 0.01 \mathrm{~m}$. Considering Tab. 1 and Fig. 1, it was defined that the OWC-WEC is placed in a distance of $2.0 \mathrm{~m}$ (two times the wave length) from the wave maker. Thus, it was estimated that the stabilization of generated waves, in the region of OWC, occurs after the third wave, i.e., when $t \geq 2.4 \mathrm{~s}$. For each simulation a time step of $0.001 \mathrm{~s}$ was employed to discretize a total time of $4.8 \mathrm{~s}$ (representing eight wave periods), in which the effects of wave reflection does not exist because the wave tank has a length of $L_{T}=5.00 \mathrm{~m}$.

It were evaluated the mass flow rate (in the chimney outlet), the pressure (inside the chamber), as well as the OWC hydro-pneumatic power, considering a time interval of $2.4 \mathrm{~s} \leq t \leq 4.8 \mathrm{~s}$. The average values were calculated employing the Root Mean Square (RSM) which is a statistical technique applied for varying quantities and is given by (Marjani et al., 2006): 


$$
X=\sqrt{\frac{1}{T} \int_{0}^{T} x^{2} d t}
$$

The mean values obtained for mass flow rate, pressure and hydro-pneumatic chamber were presented in Table 3. It is worth to mention that any flow restriction representing the head loss caused by the turbine was considered. So, the available hydropneumatic power was evaluated by (Dizadji and Sajadian, 2011; Oliveira, 2012):

$$
P_{h y d}=\left(P_{a i r}+\frac{\rho_{a i r} v_{a i r}^{2}}{2}\right) \frac{\dot{m}}{\rho_{\text {air }}}
$$

where: $P_{\text {air }}$ is the static pressure in the OWC chimney $(\mathrm{Pa}), \rho_{\text {air }}$ is the air density $\left(\mathrm{kg} / \mathrm{m}^{3}\right), \dot{m}$ is the air mass flow rate crossing the chimney $(\mathrm{kg} / \mathrm{s})$, $v_{\text {air }}$ is the air velocity in the chimney $(\mathrm{m} / \mathrm{s})$ given by:

$$
v_{\text {air }}=\frac{\dot{m}}{A \rho_{\text {air }}}
$$

being $A$ the cross sectional area of the chimney.

\begin{tabular}{|c|c|c|c|c|c|c|}
\hline $\begin{array}{l}\text { ये } \\
\text { జ్ }\end{array}$ & $\underset{\Sigma}{\triangleq}$ & 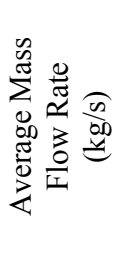 & 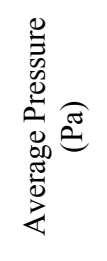 & 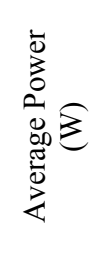 & 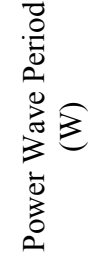 & 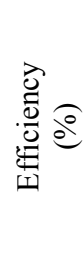 \\
\hline 1 & 0.14 & 0.3450 & 3.9048 & 0.0823 & 0.3437 & 2.23 \\
\hline 2 & 0.28 & 0.5321 & 5.9500 & 0.2135 & 1.8668 & 12.16 \\
\hline 3 & 0.42 & 0.6065 & 7.0401 & 0.3146 & 2.9860 & 19.45 \\
\hline 4 & 0.56 & 0.6267 & 7.4167 & 0.3503 & 3.5033 & 22.82 \\
\hline 5 & 0.70 & 0.6300 & 7.3061 & 0.3541 & 3.5529 & 23.14 \\
\hline 6 & 0.84 & 0.6244 & 7.6967 & 0.3671 & 3.6677 & 23.89 \\
\hline 7 & 0.98 & 0.6159 & 7.6392 & 0.3638 & 3.6007 & 23.46 \\
\hline 8 & 1.26 & 0.5881 & 7.3223 & 0.3379 & 3.2858 & 21.40 \\
\hline 9 & 2.24 & 0.5382 & 6.7528 & 0.2922 & 2.7607 & 17.98 \\
\hline
\end{tabular}

Table 3. Results for mass flow rate, pressure, power and efficiency.

The results of Table 3 indicated that varying the degree of freedom $H_{1} / L$ the maximum values of mass flow rate, pressure and hydro-pneumatic power were concentrated among cases 3 and 7, i.e., for an OWC length between $0.37 \mathrm{~m}$ and $0.57 \mathrm{~m}$ representing, respectively, $1 / 3$ and $1 / 2$ of the wave length generated in the wave tank. This fact was more evident when the average values of mass flow rate (Fig. 2a) and hydro-pneumatic power (Fig. 2b) are plotted as functions of $H_{1} / L$.

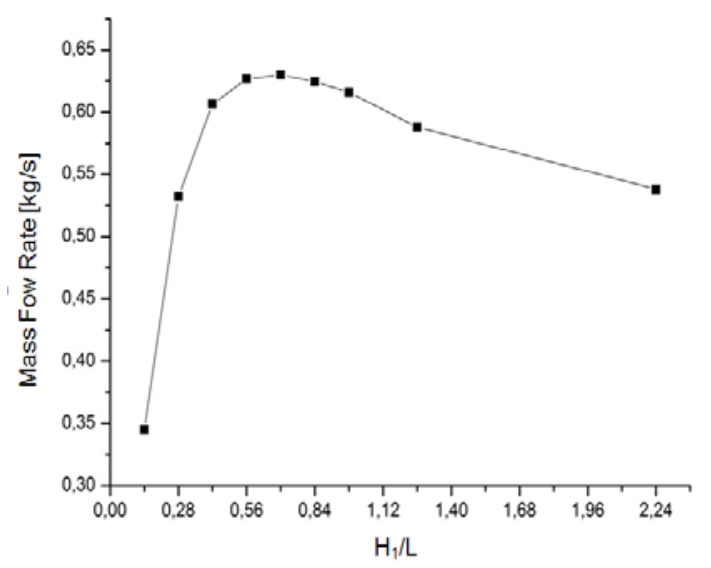

(a)

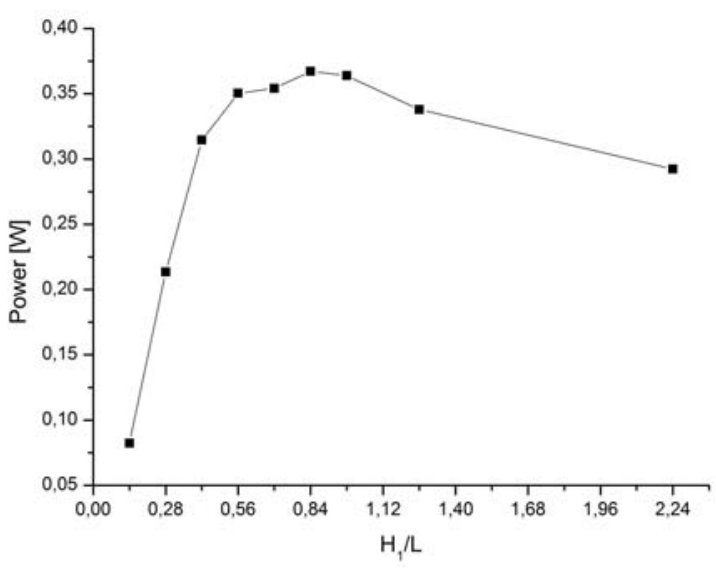

(b)

Figure 2. RMS value of Mass flow rate (a) and Hydro-pneumatic power (b) as function of $H_{1} / L$.

Since the objective function was to maximize the hydro-pneumatic power, analyzing Table 3 and Fig. 2(b) it was possible to define the Case 6 as optimal geometry. Therefore the optimal geometry was obtained with $H_{1} / L=0.84, H_{1}=0.3429 \mathrm{~m}$ (equivalent to $7 / 20$ of incident wave height) and $L=0.4082 \mathrm{~m}$ (equivalent to $2 / 5$ of incident wave length).

The OWC efficiency is another aspect that corroborates the Case 6 as the optimal geometry. It is possible to define the OWC efficiency by the ratio between hydro-pneumatic power (absorbed from the wave by the OWC-WEC) and the incident wave power (Gomes, 2010). In accordance with McCormick (1981) the incident wave power is defined as:

$$
P_{i}=\frac{\rho g}{8} H^{2} c_{g} b\left[1+\frac{9}{64} \frac{H^{2}}{k^{4} h^{6}}\right]
$$

where: $\rho$ is the water density $\left(\mathrm{kg} / \mathrm{m}^{3}\right), g$ is the gravity acceleration $\left(\mathrm{m} / \mathrm{s}^{2}\right), H$ is the wave height, $c_{g}$ 
is the wave celerity $(\mathrm{m} / \mathrm{s}), b$ is the OWC width $(\mathrm{m}), k$ is the wave number and $h$ is the water depth $(\mathrm{m})$.

Considering the characteristics of the generated waves, it was obtained an incident wave power of $15.1481 \mathrm{~W}$ per meter of wave front. Since it were developed 2D numerical simulations, the OWC width was considered unitary. Besides, the low magnitude of the incident wave power can be explained by the fact that the generated waves are in laboratory scale. So, the hydro-pneumatic power was calculated for one wave period $(4.0 \mathrm{~s} \leq t \leq 4.8 \mathrm{~s})$, and results were presented in Table 3 , as well as, its efficiency values. It is important to emphasize that the obtained results are promising because in this study the turbine head loss was not deemed (generating a lower pressure inside the OWC-WEC).

\section{CONCLUSIONS}

A geometric optimization of an OWC-WEC was performed by means of Constructal Design method associated with computational modeling. An optimal geometry for the OWC-WEC was obtained for the degree of freedom $H_{1} / L=0.84$. This optimal case presents an efficiency around ten times superior of the worst case $\left(H_{1} / L=0.14\right)$, representing an improvement higher than $20 \%$ in the OWC-WEC performance. Therefore, the applicability of the Constructal Design method to geometrically optimize the WECs was established, as already observed in Lopes et al. (2012) and Machado et al. (2012).

The obtained results are promising, because using the Constructal Design it was possible to define an optimal geometric configuration for the OWCWEC, i.e., a geometry that make the most of incident wave energy. Moreover, due to the applied Constructal Design formulation the OWC-WEC geometry was related with the incident wave characteristics. Accordingly, if the real wave climate is known it is possible to indicate the optimal dimensions of OWC that will lead a better performance.

The sequence of the present work is to consider the turbine head loss in the computational model, as well as, to use the Constructal Design for a threedimensional model in real scale.

\section{ACKNOWLEDGEMENTS}

The authors thank to Universidade Federal de Rio Grande (FURG), Universidade Federal do Rio Grande do Sul (UFRGS), Instituto Federal do Paraná (IFPR), FAPERGS and CNPq (Process no.: 555695/2010-7) for the financial support. L. A. O. Rocha also thanks CNPq for the research grant and E. D. dos Santos thanks FAPERGS by financial support (Process: 12/1418-4).

\section{REFERENCES}

Aneel, 2008, Atlas de Energia Elétrica no Brasil, $3^{\mathrm{a}}$ ed., Agência Nacional de Energia Elétrica. (in Portuguese)

Bejan, A., 2000, Shape and Structure, from Engineering to Nature, Cambridge University Press, Cambridge.

Bejan, A., and Lorente, S., 2008, Design with Constructal Theory, Wiley.

Bejan, A., and Zane J., 2012, Design in Nature, Doubleday.

Carter, R. W., 2005, Wave Energy Converters and a Submerged Horizontal Plate, Master Thesis, Master of Science in Ocean and Resources Engineering, University of Hawaii, Manoa, Honolulu.

Chakrabarti, S. K., 2005, Handbook of Offshore Engineering, Vol. 1, Elsevier.

Cruz, J. M. B. P., and Sarmento, A. J. N. A., 2004, Energia das Ondas: Introdução aos Aspectos Tecnológicos, Econômicos e Ambientais, Instituto do Ambiente, Amadora. (in Portuguese)

Dizadji, N., and Sajadian, S. E., 2011, Modeling and Optimization of the Chamber of OWC System, Energy, Vol. 36, pp. 2360-2366.

Fluent Inc., 2005, FLUENT 6.2 User's Guide.

Gomes, M. das N., Olinto, C. R. , Rocha, L. A. O., Souza, J. A., and Isoldi, L. A., 2009, Computational Modeling of a Regular Wave Tank, Engenharia Térmica, Vol. 8, No.1, pp. 44-50.

Gomes, M. das N., 2010, Modelagem Computacional de um Dispositivo Coluna d'Água Oscilante de Conversão de Energia das Ondas do Mar em Energia Elétrica, Master Thesis, PPGMC-FURG, Rio Grande, RS. (in Portuguese)

Gomes, M. das N., Isoldi, L. A, Santos E. D., and Rocha, L. A. O., 2012, Análise de Malhas para Geração Numérica de Ondas em Tanques, in: VII Congresso Nacional de Engenharia Mecânica. São Luiz, MA, pp. 1-10. (in Portuguese)

Horko, M., 2007, CFD Optimization of an Oscillating Water Column Energy Converter, Master Thesis, Science and Engineering, School of Mechanical Engineering, University of Western, Australian.

Liu, Z., Hyun B., and Hong, K., 2008a, Application of Numerical Wave Tank to OWC Air Chamber for Wave Energy Conversion, in: International Offshore and Polar Engineering Conference, Vancouver, BC, Canada, pp. 350-356

Liu, Z., Hyun B., and Jin, J., 2008b , Numerical Prediction for Overtopping Performance of OWEC, Journal of the Korean Society for Marine Environmental Engineering, Vol. 11, No. 1, pp. $35-41$.

Liu, Z., Hyun B., and Hong, K., 2011, Numerical Study of Air Chamber for Oscillating Water Column Wave Energy Convertor, China Ocean Eng., Vol. 25, pp.169-178. 
Lopes, N. R., Sant'Anna, F. S. P., Gomes, M. N., Souza, J. A., Teixeira, P. R. F., Dos Santos, E. D., Isoldi, L. A., and Rocha, L. A. O., 2012, Constructal Design Optimization of the Geometry of an Oscillating Water Column Wave Energy Converter (OWC-WEC), in: Proceedings Constructal Law Conference, UFRGS, Porto Alegre.

Machado, B. N., Zanella, M. M., Gomes, M. N., Teixeira, P. R. F., Isoldi, L. A., Dos Santos, E. D., and Rocha, L. A. O., 2012, Constructal Design of an Overtopping Wave Energy Converter, in: Proceedings Constructal Law Conference, UFRGS, Porto Alegre.

Marjani, A. E., Castro, F., Bahaji, M., and Filali, B., 2006, 3D Unsteady Flow Simulation in an OWC Wave Converter Plant, in: Proceedings International Conference on Renewable Energy and Power Quality, Mallorca, Espanha.

McCormick, M. E., 1981, Ocean Energy Conversion, John Wiley \& Sons.

Ramalhais, R. dos S., 2011, Estudo Numérico de um Dispositivo de Conversão da Energia das Ondas do Tipo Coluna de Água Oscilante (CAO), Master Thesis, Faculdade de Ciências e Tecnologia da Universidade Nova de Lisboa, Lisboa, Portugal. (in Portuguese)

Versteeg, H. K.; and Malalasekera, W., 2007, An Introduction to Computational Fluid Dynamics The Finite Volume Method, Pearson.

Received: September 30, 2012

Revised: October 30, 2012

Accepted: November 30, 2012 